\title{
The impact of the alveolar bone sites on early implant failure: a systematic review with meta-analysis
}

\author{
Atef Abdel Hameed Fouda \\ Department of Maxillofacial Surgery, Kasr El Eyne Hospital, Cairo University, Cairo, Egypt
}

\begin{abstract}
J Korean Assoc Oral Maxillofac Surg 2020;46:162-173)
Dental implants are the first option for replacement of missing teeth. Failure usually involves additional cost and procedures. As a result, the physician should limit the risk factors associated with implant failures. Implant site is one of many factors that can influence the success or failure of dental implants. The association between early implant failure (EIF) and implant site has yet to be documented. This review aims to estimate the impact of insertion site on the percentage of EIFs. An electronic and manual search of studies that reported early failure of dental implants based on collection site. A total of 21 studies were included in the review and examined for the association between EIF and alveolar site. Subgroup analysis, including a comparison between implants inserted in four alveolar ridge regions of both jaws was performed. The early failure rate was higher for maxillary implants (3.14\%) compared to mandibular implants (1.96\%). Applying a random effect, risk ratio (RR), and confidence interval (CI) of $95 \%$ revealed higher failure in the maxilla compared to the mandible (RR $1.41 ; 95 \%$ CI $[1.19,1.67] ; P<0.0001 ; I^{2}=58 \%$ ). The anterior maxilla is more critical for early implant loss than other alveolar bone sites. Implants in the anterior mandible exhibited the best success rate compared of the sites.
\end{abstract}

Key words: Dental implantation, Osseointegrated, Peri-implant endosseous healing, Bone implant interface

[paper submitted 2019. 12. 23 / revised 1st 2020. 3. 15, 2nd 2020. 3. 25 / accepted 2020. 4. 1]

\section{Introduction}

Implant failure is the term used for dental implants that require removal or are lost. Early implant failure (EIF) is defined as implant failure before being put into use, i.e., preprosthetic phase ${ }^{1}$.

Despite the progressive increase in the success rate of dental implants, a certain percentage of implant failures remain with unknown etiologies. Clinicians should be aware of any potential risk that may affect implant osseointegration and failure $^{2,3}$.

Among the local causes of EIF is poor bone quality, a lack of primary stability due to surgical trauma, and infection that disturbs primary bone healing ${ }^{3}$. Other systemic conditions

\footnotetext{
Atef Abdel Hameed Fouda

Department of Maxillofacial Surgery, Kasr El Eyne Hospital, Cairo

University, Cairo, Egypt

TEL: +20-1093440600 FAX: +20-23642938

E-mail:Atef.fouda@dentistry.cu.edu.eg

ORCID: https://orcid.org/0000-0001-6386-3696

(c) This is an open-access article distributed under the terms of the Creative Commons Attribution Non-Commercial License (http://creativecommons.org/ licenses/by-nc/4.0/), which permits unrestricted non-commercial use, distribution, and reproduction in any medium, provided the original work is properly cited.

Copyright (C) 2020 The Korean Association of Oral and Maxillofacial Surgeons. All rights reserved.
}

that influence the initial healing process of bone include uncontrolled diabetes mellitus, osteoporosis, corticosteroids, bisphosphonate therapy, and collagen disorders ${ }^{3-5}$.

Implant site is among the biological factors that may affect implant survival. There has been considerable debate regarding implant site and failure ${ }^{6-8}$. Several studies have tried to compare implant failure rates regarding implant insertion region of the jaw. Studies have reported that implants fail in the maxilla more than the mandible ${ }^{9-13}$. Furthermore, the maxillary anterior region exhibited the highest rate of implant failure. Factors contributing to higher implant failure in the maxillary arch compared to mandibular arch are not yet understood $^{14,15}$. The high implant failure rate observed in the maxilla suggests that low bone density may be a contributing factor responsible for $\mathrm{EIF}^{15}$. Smoking may modulate implant failure by influencing bacterial infections in the maxillary and mandibular arches ${ }^{16}$.

Many clinical trials have evaluated the locations of implants and concluded that implants inserted in the anterior maxilla failed more than those placed in the posterior maxilla. Moreover, failures in the anterior mandible are more common than posterior failures, with the posterior maxilla recording the highest rate of failure ${ }^{15}$. A recent study reported that the 
two jaw bones exhibited the same rate of implant failure and stated that implantation site is not a modulating factor influencing EIF rate ${ }^{17}$.

EIF is among the worst problems in implantology. Inappropriate surgical protocols, surgical difficulties, decrease in bone volume or quality at the recipient site, and systemic conditions are all confounding factors ${ }^{14}$.

Implantation sites could play an influential role in the occurrence of EIF. Therefore, the purpose of this systematic review is to analyze high-quality studies to determine if there is a correlation between early failure and implantation site.

\section{Materials and Methods}

The recommendations of the PRISMA (Preferred Reporting Items for Systematic Reviews and Meta-Analyses) statement are as follows ${ }^{18}$.

\section{Research question}

Is there is any correlation between site of implantation (maxillary anterior, maxillary posterior, mandibular anterior, or mandibular posterior) and EIF?

\section{Search strategy}

MEDLINE, EMBASE, Web of Science, Cochrane Library, and Egyptian Knowledge Bank (EKB) were individually searched for studies in English from the year 1998 to the present. Manual searches were performed to identify references from primary studies and systematic reviews for relevant data.

The search used a combination of controlled vocabulary “Dental implants"[MeSH Terms] OR ("oral implants"[All Fields] AND "failure"[All Fields] AND “early"[All Fields]) OR "titanium dental implants"[All Fields] OR "early implant failure"[All Fields] OR “dental implant site"[All Fields].

\section{Study selection}

All abstracts and full articles were screened, and the following inclusion and exclusion criteria were applied.

\section{Inclusion criteria}

The chosen studies met the criteria of retrospective, prospective, and randomized clinical trials; all age ranges; both sexes; all types of implants either inserted into the drilled site or after use of an osteotome; all patients regardless of smoking status and use of antibiotics.

\section{Exclusion criteria}

Studies that were excluded from the analysis were those on cadavers, animals, patients with systemic problems affecting bone density or mineralization, patients under treatment with corticosteroids or bisphosphonate therapy, reported failures after prosthetic fixation, implantation in grafted sites, or after sinus lift procedures.

\section{Data extraction}

The extracted data are shown in a table and comprise authors, publication year, study type, site of implantation, number of implants, number of failed implants, and study power.

\section{Quality assessment}

Most of the included studies were retrospective. Randomized or blinded studies were impossible, and studies with small sample size or improper methodology were rejected.

\section{Assessment of heterogeneity}

The chi-square test for heterogeneity was performed, and the extent of the inconsistency of treatment effects $\left(\mathrm{I}^{2}\right)$ across trials was measured.

We considered heterogeneity as substantial if $\mathrm{I}^{2}$ was greater than $30 \%$ or if there was a low $P$-value (less than 0.10 ) in the chi-square test for heterogeneity.

We used a fixed-effect meta-analysis for combining data to assume that the studies were estimating the same underlying treatment effect. If there was clinical heterogeneity sufficient to expect that the underlying treatment effects differed between trials or if substantial statistical heterogeneity was detected, we explored this followed by random-effects and subgroup analyses.

\section{Assessment of reporting biases}

Publication bias was appraised using the visual assessment of symmetry of funnel plots. If asymmetry was detected, we performed exploratory analyses to investigate it. 


\section{Methodological quality assessment}

Data synthesis and meta-analysis were performed according to the rules adopted by the Cochrane Collaboration reviewer's handbook ${ }^{19}$. All statistical analyses were conducted using the Review Manager software (RevMan ver. 5.3).

\section{Meta-analysis}

The dichotomous analysis in the form of number of failed implants in proportion to total implants inserted was analyzed with a risk ratio (RR) (relative risk) and $95 \%$ confidence interval (CI) for each study. Random effects were selected in the comparison of maxillary and mandibular implant failures because of heterogeneity. Subgroup analysis of anterior and posterior sites in both bones was performed with a fixed effect and 95\% CI for accurate results. Risk difference (RD) (absolute risk) was used to declare the results and extraction of the conclusions.

\section{Results}

\section{Study selection}

After searching the electronic databases, 341 publications were identified; 17 more articles were added after a manual search (total of 358). Removal of duplicates (120 studies) left 238 studies, studies not meeting the inclusion criteria were rejected (136 studies), and the remaining 102 studies were subjected to full-text reading. Among them, 74 studies were excluded because of insufficient data, 7 studies had methodology bias, and a final total of 21 studies $^{4,10,14,15,20-36}$ were included in this review.(Fig. 1)

\section{Study characteristics}

Details of the included studies are overviewed in Table 1.

\section{Implant failure: Comparison of implant failures in the} maxilla and mandible

Analysis of the included 21 studies involved a total of 78,230 implants, among them 39,468 implants in the upper
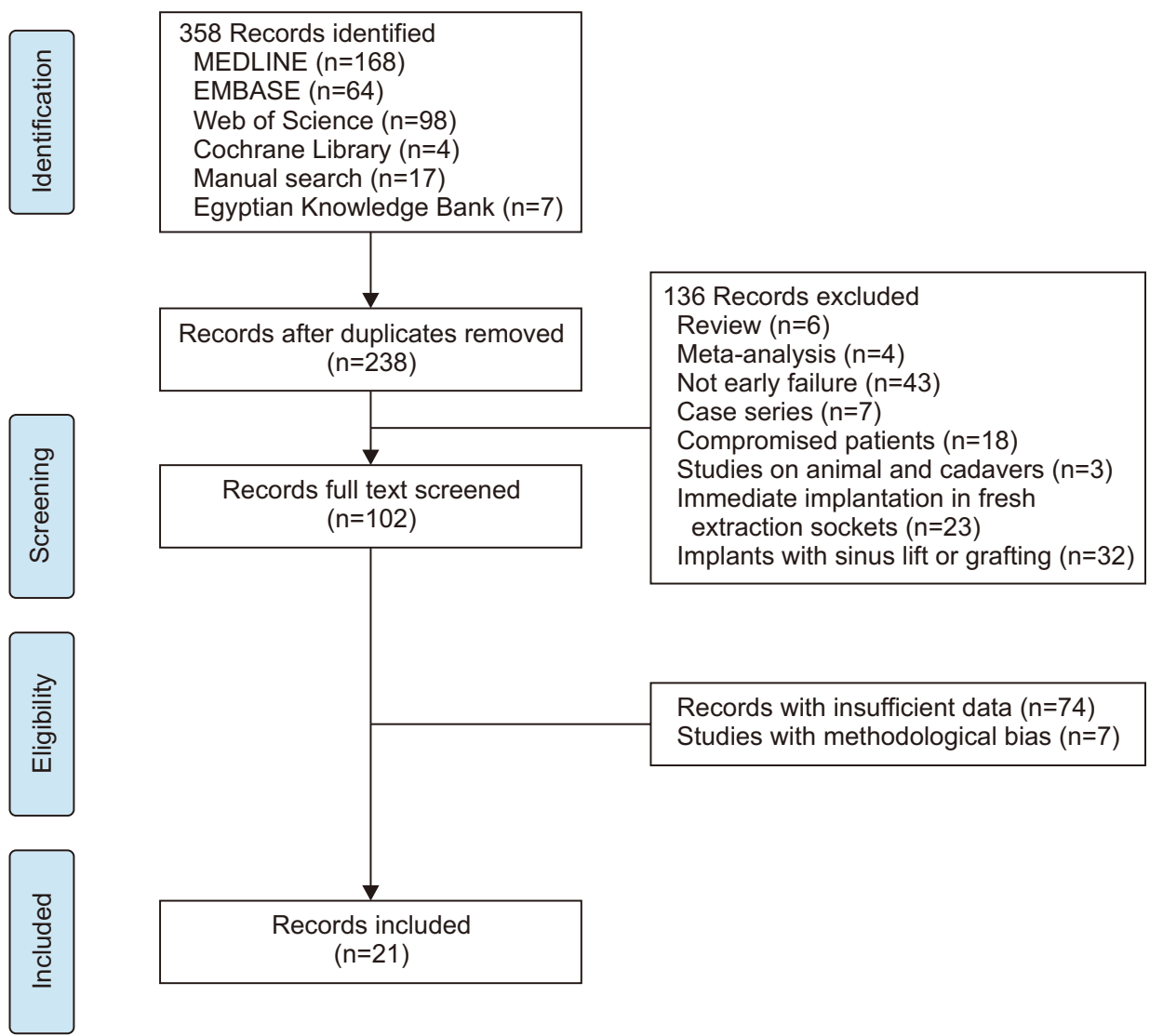

Fig. 1. Study flow diagram. Adapted from the article of Moher et al. (PLoS Med 2009;6:e1000097) ${ }^{18}$ in accordance with the Creative Commons Attribution license.

Atef Abdel Hameed Fouda: The impact of the alveolar bone sites on early implant failure: a systematic review with meta-analysis. J Korean Assoc Oral Maxillofac Surg 2020 
jaw bone and 38,762 implants placed in the lower jaw bone. A total of 1,239 implants failed in the upper jaw (3.14\%) and 759 implants failed in the lower jaw (1.96\%).

Total subgroup analysis of the 21 identified studies ${ }^{4,10,14,15,20-36}$ applying a random effect, RR, and CI of $95 \%$ revealed higher failure in the maxilla compared to the mandible (RR 1.41; 95\% CI [1.19, 1.67]; $P<0.0001 ; \mathrm{I}^{2}=58 \%$ ).
(Fig. 2) The RD analysis showed a 1\% increase in the maxilla compared to the mandible.

Table 1. Details of the studies

\begin{tabular}{|c|c|c|c|c|c|c|}
\hline Author & Year & Site & $\begin{array}{c}\text { Total } \\
\text { implants }\end{array}$ & Failures & Implant type & Type of study \\
\hline \multirow[t]{2}{*}{ Lambert et al. $^{20}$} & 2000 & Maxilla & 793 & 51 & N/A & Prospective study \\
\hline & & Mandible & 1,135 & 64 & & \\
\hline \multirow[t]{4}{*}{ Noguerol et al. ${ }^{21}$} & 2006 & Maxilla, anterior & 317 & 18 & Nobel Biocare & Retrospective study \\
\hline & & Mandible, anterior & 190 & 2 & & \\
\hline & & Maxilla, posterior & 334 & 22 & & \\
\hline & & Mandible, posterior & 243 & 13 & & \\
\hline \multirow[t]{4}{*}{ Alsaadi et al. ${ }^{22}$} & 2007 & Maxilla, anterior & 1,953 & 69 & Brånemark & Retrospective study \\
\hline & & Mandible, anterior & 1,920 & 46 & & \\
\hline & & Maxilla, posterior & 1,529 & 74 & & \\
\hline & & Mandible, posterior & 1,277 & 63 & & \\
\hline \multirow[t]{4}{*}{ Alsaadi et al. ${ }^{23}$} & 2008 & Maxilla, anterior & 181 & 4 & Ti Unite & Prospective study \\
\hline & & Mandible, anterior & 154 & 1 & & \\
\hline & & Maxilla, posterior & 199 & 4 & & \\
\hline & & Mandible, posterior & 172 & 5 & & \\
\hline \multirow[t]{4}{*}{ Bornstein et al. $^{24}$} & 2008 & Maxilla, anterior & 499 & 2 & N/A & Retrospective study \\
\hline & & Mandible, anterior & 158 & 2 & & \\
\hline & & Maxilla, posterior & 578 & 4 & & \\
\hline & & Mandible, posterior & 582 & 5 & & \\
\hline \multirow[t]{4}{*}{ Baqain et al. $^{4}$} & 2012 & Maxilla, anterior & 64 & 2 & Xive (Friadent), & Prospective study \\
\hline & & Mandible, anterior & 37 & 2 & ITI, Straumann & \\
\hline & & Maxilla, posterior & 136 & 7 & & \\
\hline & & Mandible, posterior & 162 & 4 & & \\
\hline \multirow[t]{2}{*}{ Mangano et al. ${ }^{25}$} & 2014 & Maxilla & 727 & 12 & Locking- & Prospective study \\
\hline & & Mandible & 767 & 7 & taper implants & \\
\hline \multirow[t]{4}{*}{ Geckili et al. ${ }^{14}$} & 2014 & Maxilla, anterior & 257 & 12 & N/A & Retrospective study \\
\hline & & Mandible, anterior & 499 & 11 & & \\
\hline & & Maxilla, posterior & 399 & 10 & & \\
\hline & & Mandible, posterior & 501 & 5 & & \\
\hline \multirow[t]{4}{*}{ Brügger et al. $^{26}$} & 2015 & Maxilla, anterior & 339 & 4 & N/A & Retrospective study \\
\hline & & Mandible, anterior & 179 & 0 & & \\
\hline & & Maxilla, posterior & 832 & 4 & & \\
\hline & & Mandible, posterior & 632 & 5 & & \\
\hline \multirow{4}{*}{ Chrcanovic et al. ${ }^{28}$} & 2016 & Maxilla, anterior & 1,213 & 73 & N/A & Retrospective study \\
\hline & & Mandible, anterior & 947 & 25 & & \\
\hline & & Maxilla, posterior & 698 & 41 & & \\
\hline & & Mandible, posterior & 691 & 40 & & \\
\hline \multirow[t]{2}{*}{ Oztel et al. ${ }^{10}$} & 2017 & Maxilla & 155 & 12 & N/A & Retrospective study \\
\hline & & Mandible & 147 & 3 & & \\
\hline \multirow[t]{2}{*}{ Borba et al. $^{29}$} & 2017 & Maxilla & 392 & 20 & N/A & Cross-sectional \\
\hline & & Mandible & 382 & 5 & & \\
\hline \multirow[t]{5}{*}{ Hickin et al. ${ }^{30}$} & 2017 & Maxilla, anterior & 1,115 & 55 & Nobel Biocare, & Retrospective study \\
\hline & & Mandible, anterior & 705 & 17 & Replace, Select, & \\
\hline & & Maxilla, posterior & 2,470 & 68 & Active, Groovy, & \\
\hline & & Mandible, posterior & 1,839 & 39 & Straumann, & \\
\hline & & & & & $\begin{array}{l}\text { SLActive, SLA, } \\
\text { Biomet 3i, all T3, } \\
\text { Nanotite, Osseotite, } \\
\text { Keystone, Dentium }\end{array}$ & \\
\hline \multirow[t]{4}{*}{ Chrcanovic et al. ${ }^{32}$} & 2017 & Maxilla, anterior & 1,214 & 73 & Nobel turned, Nobel & Retrospective \\
\hline & & Mandible, anterior & 950 & 25 & TiUnite, Astra & cohort study \\
\hline & & Maxilla, posterior & 704 & 41 & TiOblast, Straumann. & \\
\hline & & Mandible, posterior & 691 & 39 & Xive, Frialit-2 & \\
\hline
\end{tabular}


Table 1. Continued

\begin{tabular}{|c|c|c|c|c|c|c|}
\hline Author & Year & Site & $\begin{array}{l}\text { Total } \\
\text { implants }\end{array}$ & Failures & Implant type & Type of study \\
\hline Chrcanovic et al. ${ }^{27}$ & 2017 & $\begin{array}{l}\text { Maxilla, anterior } \\
\text { Mandible, anterior } \\
\text { Maxilla, posterior } \\
\text { Mandible, posterior }\end{array}$ & $\begin{array}{l}3,252 \\
2,162 \\
1,748 \\
1,768\end{array}$ & $\begin{array}{r}263 \\
65 \\
137 \\
88\end{array}$ & $\begin{array}{l}\text { Nobel turned, Nobel } \\
\text { TiUnite, Astra } \\
\text { TiOblast, Straumann, } \\
\text { Xive, Frialit-2 }\end{array}$ & Retrospective study \\
\hline Hasegawa et al. ${ }^{36}$ & 2017 & $\begin{array}{l}\text { Maxilla } \\
\text { Mandible }\end{array}$ & $\begin{array}{l}421 \\
463\end{array}$ & $\begin{array}{l}11 \\
12\end{array}$ & $\begin{array}{l}\text { Brånemark System, } \\
\text { TiUnite, Groovy }\end{array}$ & Prospective study \\
\hline Chrcanovic et al. ${ }^{31}$ & 2017 & $\begin{array}{l}\text { Maxilla, anterior } \\
\text { Mandible, anterior } \\
\text { Maxilla, posterior } \\
\text { Mandible, posterior }\end{array}$ & $\begin{array}{l}335 \\
241 \\
167 \\
188\end{array}$ & $\begin{array}{r}15 \\
3 \\
6 \\
11\end{array}$ & $\begin{array}{l}\text { Nobel turned, Nobel } \\
\text { TiUnite, Astra } \\
\text { TiOblast, Straumann, } \\
\text { Xive, Frialit-2 }\end{array}$ & Retrospective study \\
\hline Lin et al. ${ }^{33}$ & 2018 & $\begin{array}{l}\text { Maxilla, anterior } \\
\text { Mandible, anterior } \\
\text { Maxilla, posterior } \\
\text { Mandible, posterior }\end{array}$ & $\begin{array}{r}4,381 \\
1,941 \\
9,266 \\
14,326\end{array}$ & $\begin{array}{l}29 \\
33 \\
51 \\
81\end{array}$ & $\begin{array}{l}\text { Straumann, Nobel } \\
\text { Biocare Ankylos, } \\
\text { Bego, Osstem, } \\
\text { Biconcept, SPI }\end{array}$ & Retrospective study \\
\hline Hirota et al. ${ }^{34}$ & 2018 & $\begin{array}{l}\text { Maxilla, anterior } \\
\text { Mandible, anterior } \\
\text { Maxilla, posterior } \\
\text { Mandible, posterior }\end{array}$ & $\begin{array}{r}102 \\
63 \\
160 \\
238\end{array}$ & $\begin{array}{l}3 \\
2 \\
6 \\
4\end{array}$ & Nobel Biocare & Retrospective study \\
\hline Lang et al. ${ }^{15}$ & 2019 & $\begin{array}{l}\text { Maxilla } \\
\text { Mandible }\end{array}$ & $\begin{array}{l}217 \\
214\end{array}$ & $\begin{array}{r}7 \\
7 \\
10\end{array}$ & N/A & Retrospective study \\
\hline Chatzopoulos et al. ${ }^{35}$ & 2020 & $\begin{array}{l}\text { Maxilla } \\
\text { Mandible }\end{array}$ & $\begin{array}{l}2,282 \\
2,237\end{array}$ & $\begin{array}{l}25 \\
26\end{array}$ & N/A & Retrospective study \\
\hline
\end{tabular}

(N/A: not available)

Atef Abdel Hameed Fouda: The impact of the alveolar bone sites on early implant failure: a systematic review with meta-analysis. J Korean Assoc Oral Maxillofac Surg 2020

\section{Subgroup analysis}

1) Anterior maxillary region compared with the anterior mandibular region

Data were extracted from 11 studies ${ }^{4,14,21,23,26-28,30-32,34}$ with a total of 14,516 implants. Among those implants, 8,389 were placed in the maxillary esthetic zone and 6,127 implants in the lower anterior region of the mandible. There was a total of 522 failed implants within the anterior maxillary region (6.2\%) compared to 153 failed implants within the anterior mandible region (2.5\%).

Total subgroup analysis of the 11 identified studies applying a fixed effect, RR, and CI of $95 \%$ revealed significant failure in the anterior maxilla compared to the anterior mandible (RR 2.44; 95\% CI [2.04, 2.91]; $P<0.00001 ; \mathrm{I}^{2}=0 \%$ ). (Fig. 3)

The $\mathrm{RD}$ analysis reported a 3\% increase in risk failure in the anterior maxillary region compared to the anterior mandibular region.

\section{2) Posterior maxillary region compared with the posterior} mandibular region

Data were extracted from 13 studies, ${ }^{4,14,21-24,26,28,30-34}$ with a total of 39,014 implants; among them, 17,472 were inserted into the maxillary posterior region and 21,542 in the lower posterior region of the mandible.
There was a total of 338 failed implants in the maxillary posterior region (1.9\%) compared to 314 failed implants within the mandibular posterior region (1.46\%).

Total subgroup analysis of the 13 identified studies applying a fixed effect, RR, and CI of $95 \%$ revealed a nonsignificant difference in failure between the posterior maxilla and the posterior mandible (RR 1.07; 95\% CI [0.92, 1.25]; $P=0.68 ; \mathrm{I}^{2}=0 \%$ ).(Fig. 4 )

The $\mathrm{RD}$ analysis reported the same risk in the posterior maxillary region as in the posterior mandibular region.

3) Anterior maxillary region compared with the posterior maxillary region

Data were extracted from 12 studies , $14,21,23,24,26-28,31-34$ including a total of 27,375 implants: 12,154 inserted within the maxillary anterior region and 15,221 placed in the posterior region.

A total of 498 implants failed within the anterior region (4\%) compared to 333 in the posterior region (2.19\%).

Total subgroup analysis of the 12 studies applying a fixed effect, RR, and CI of $95 \%$ revealed a non-significant difference in failure between anterior and posterior maxillary regions (RR 1.06; 95\% CI [0.92, 1.21]; $P=0.44 ; \mathrm{I}^{2}=0 \%$ ).(Fig. 5 )

The RD analysis reported the same risk of failure in both the anterior and posterior maxillary regions. 


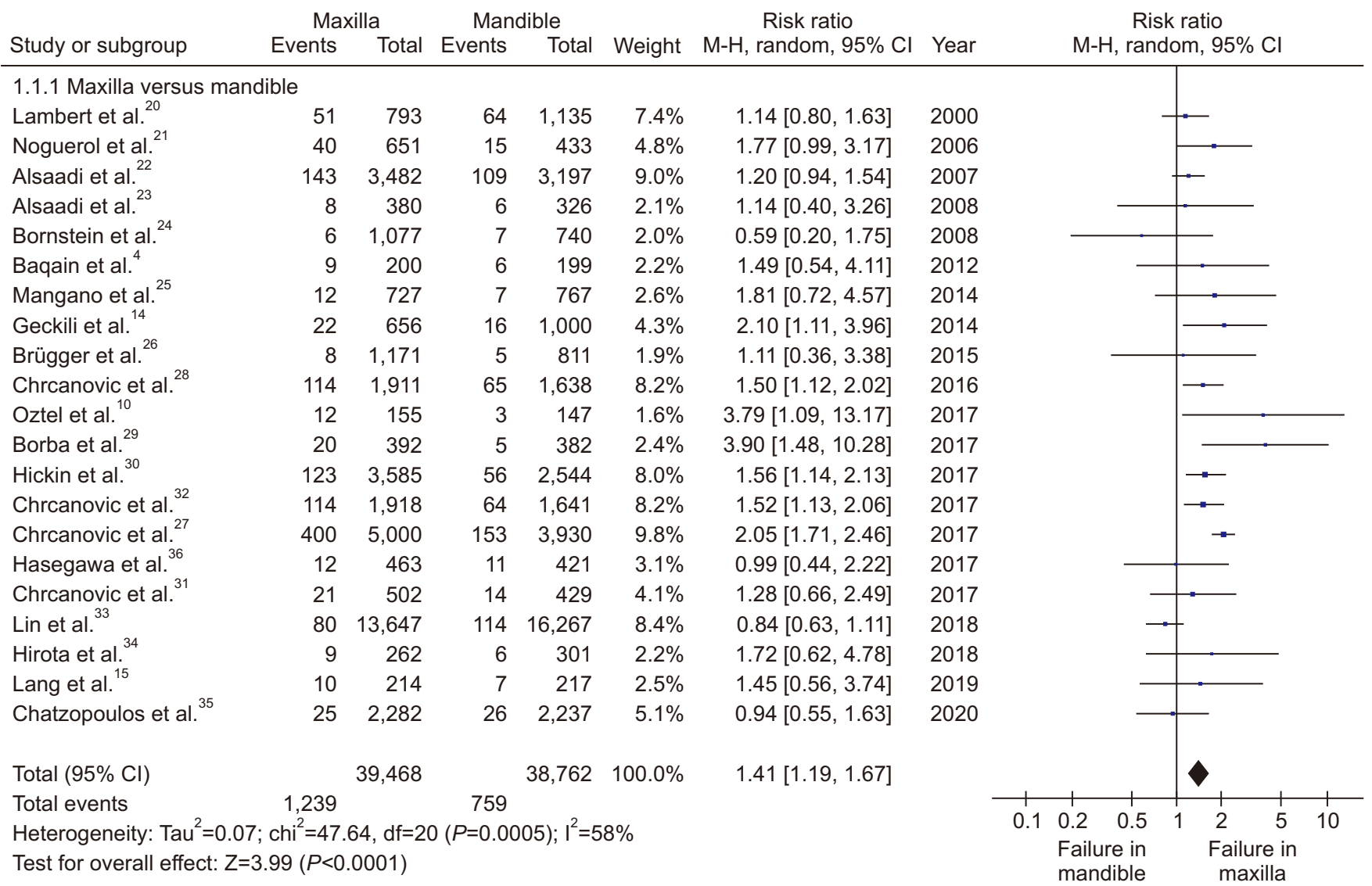

Fig. 2. Forest plot comparison: Maxilla versus mandible in early implant failures.

Atef Abdel Hameed Fouda: The impact of the alveolar bone sites on early implant failure: a systematic review with meta-analysis. J Korean Assoc Oral Maxillofac Surg 2020

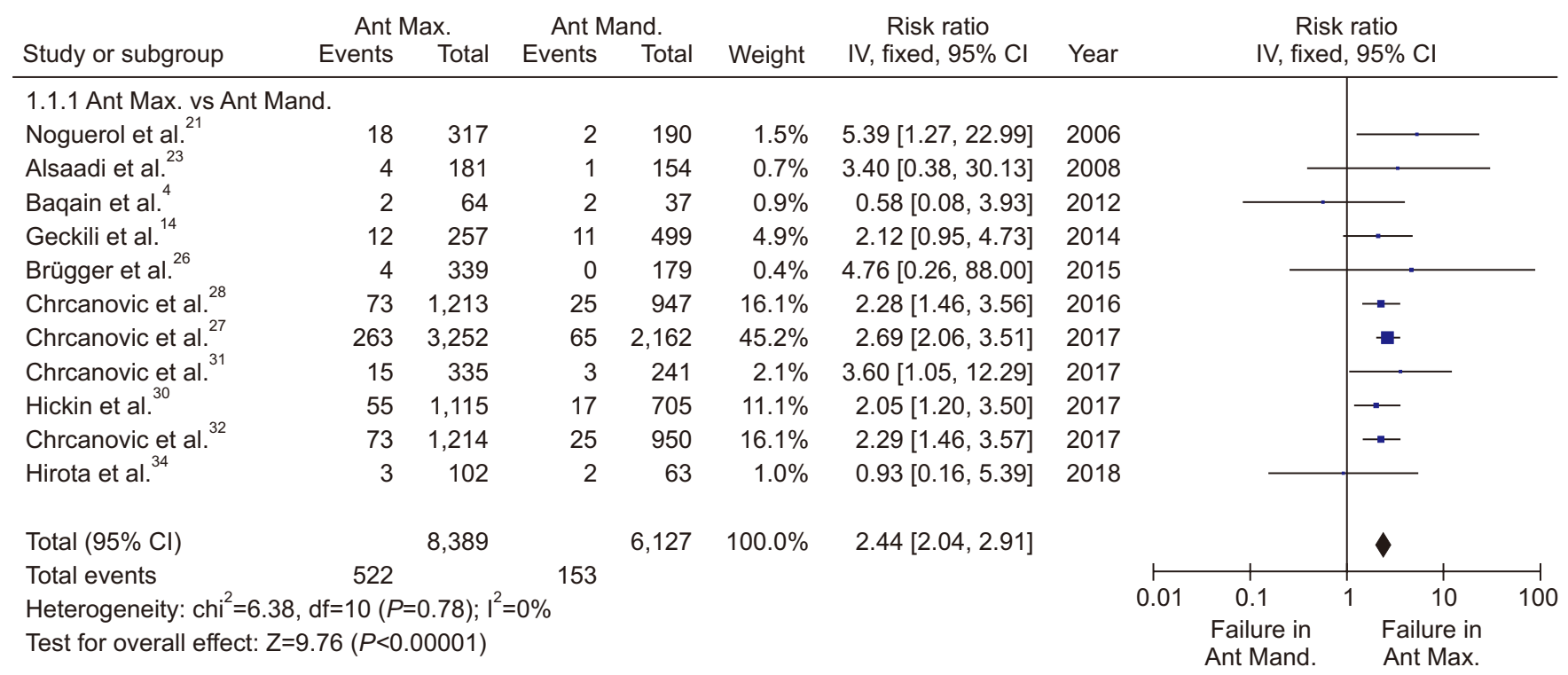

Fig. 3. Forest plot comparison: Anterior maxillary region (Ant Max.) versus anterior mandibular region (Ant Mand.) in early implant failures. Atef Abdel Hameed Fouda: The impact of the alveolar bone sites on early implant failure: a systematic review with meta-analysis. J Korean Assoc Oral Maxillofac Surg 2020

4) Anterior mandibular region compared with the posterior mandibular region

Data were extracted from nine studies ${ }^{21-24,26-28,32,34}$ with a total of 13,017 implants: 6,723 placed in the mandibular anterior region and 6,294 placed in the posterior region.

A total of 168 implants failed within the anterior region 
(2.5\%) compared to the 262 failed implants in the posterior region $(4.2 \%)$.

Total subgroup analysis of the nine identified studies applying a fixed effect, RR, and a CI of 95\% revealed a significant difference between the anterior and posterior mandibular regions, with more failures in the posterior mandible (RR 0.52 ; $95 \%$ CI $[0.43,0.62] ; P=0.46 ; \mathrm{I}^{2}=0 \%$ ).(Fig. 6 )
The analysis of $\mathrm{RD}$ reported $2 \%$ greater risk failure within the posterior mandibular region compared to the anterior region.

5) Anterior maxillary region compared with the posterior mandibular region

Data were extracted from 11 studies $^{4,21-24,26,28,31-34}$ with a total of 29,800 implants, among which 10,598 were inserted in

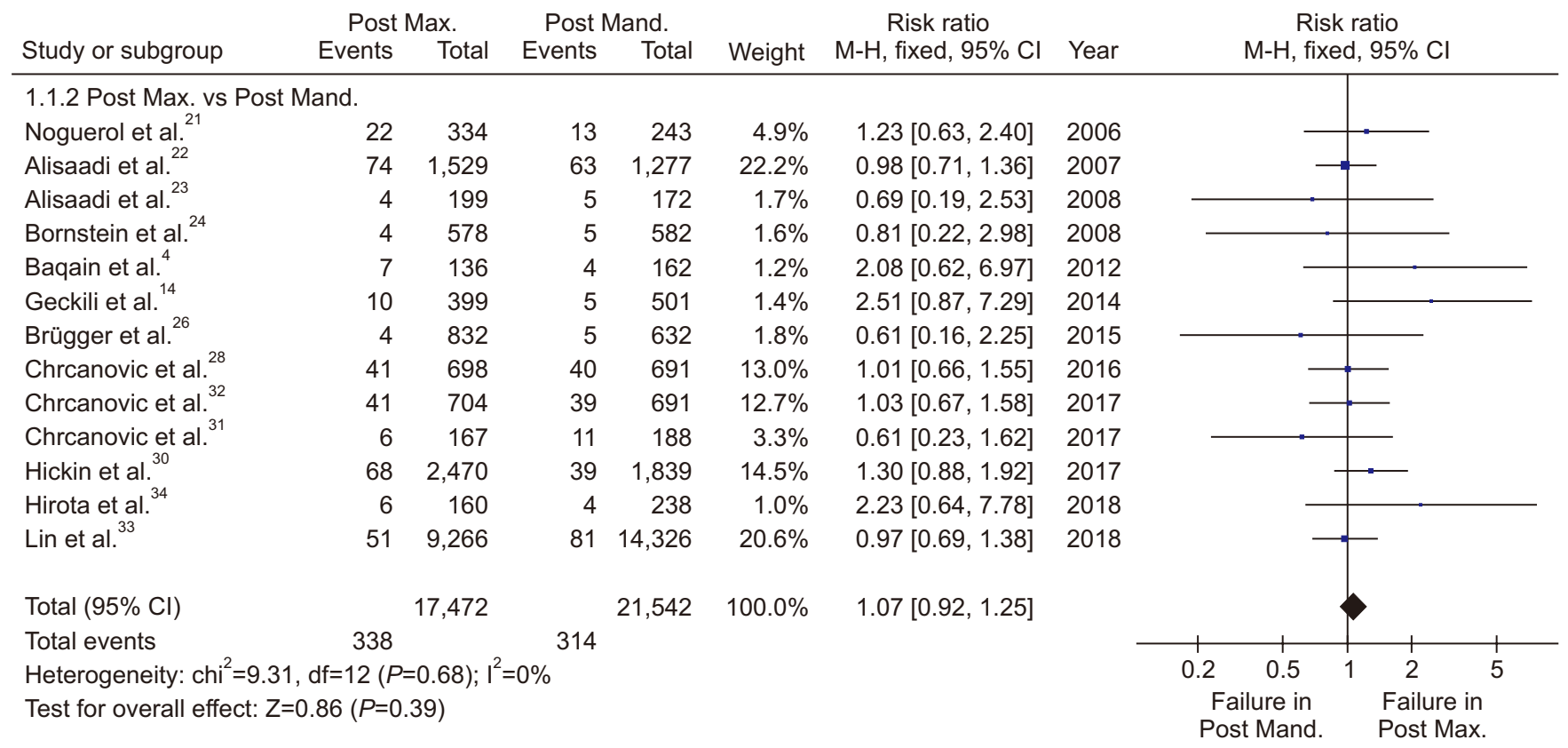

Fig. 4. Forest plot comparison: Posterior mandibular region (Post Mand.) versus posterior maxillary region (Post Max.) in early implant failures. Atef Abdel Hameed Fouda: The impact of the alveolar bone sites on early implant failure: a systematic review with meta-analysis. J Korean Assoc Oral Maxillofac Surg 2020

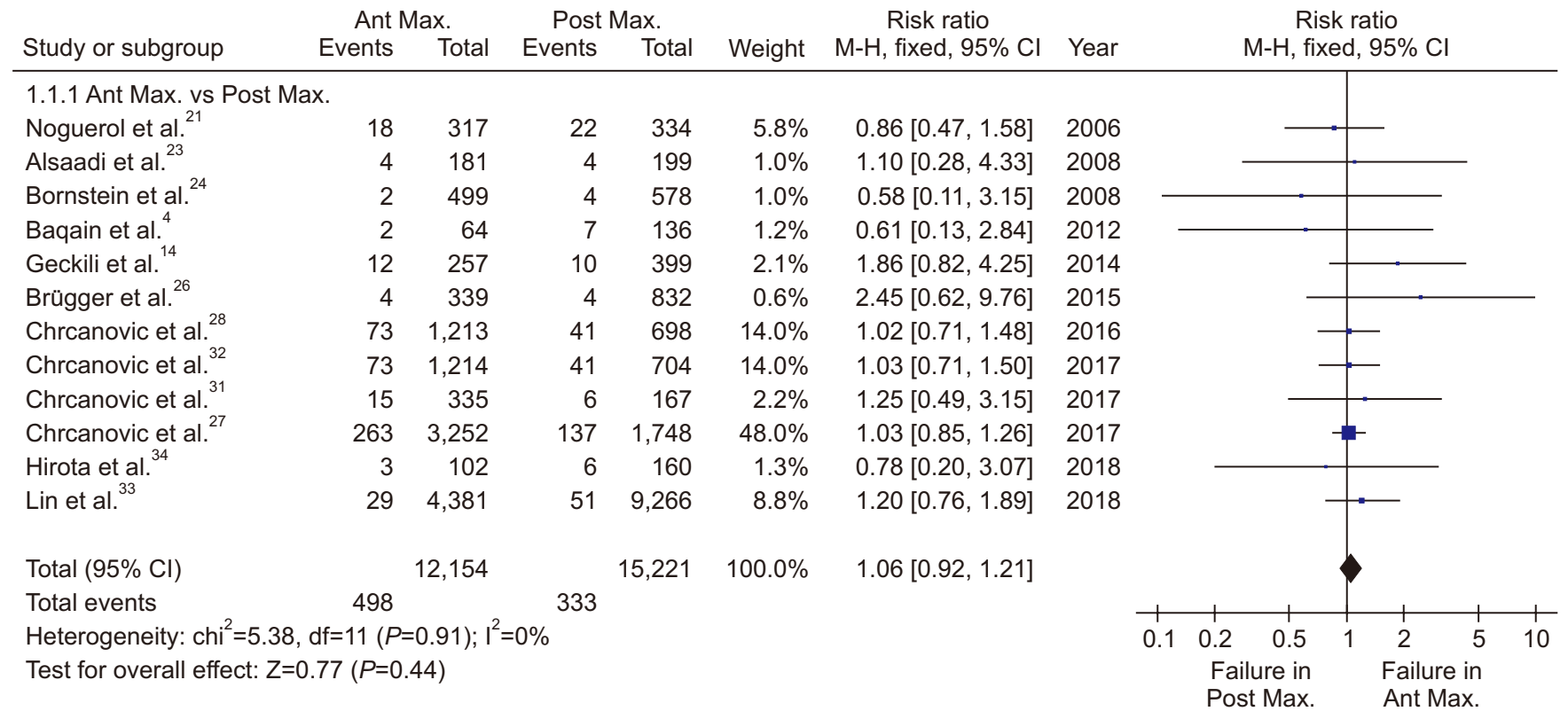

Fig. 5. Forest plot comparison: Anterior maxillary region (Ant Max.) versus posterior maxillary region (Post Max.) in early implant failures. Atef Abdel Hameed Fouda: The impact of the alveolar bone sites on early implant failure: a systematic review with meta-analysis. J Korean Assoc Oral Maxillofac Surg 2020 
the maxillary anterior region and 19,202 placed in the posterior mandibular region.

A total of 292 implants failed in the anterior maxillary region (2.8\%) compared to 270 failed implants in the posterior mandibular region $(1.4 \%)$.

Total subgroup analysis of the 11 identified studies applying a fixed effect, RR, and a CI of $95 \%$ revealed a nonsignificant difference in failure between anterior maxilla and posterior mandibular regions (RR 0.95; 95\% CI [0.81, 1.13]; $P=0.59 ; \mathrm{I}^{2}=0 \%$ ).(Fig. 7)
The RD analysis reported the same risk in the anterior maxillary and posterior mandibular regions.

6) Anterior mandibular region compared with the posterior maxillary region

Data were extracted from 12 studies $^{4,14,21-24,26-28,31,32,34}$ with a total of 14,984 implants, among which 7,500 were inserted into the anterior mandibular region and 7,484 placed in the posterior maxillary region.

A total of 184 implants failed in the anterior region of the

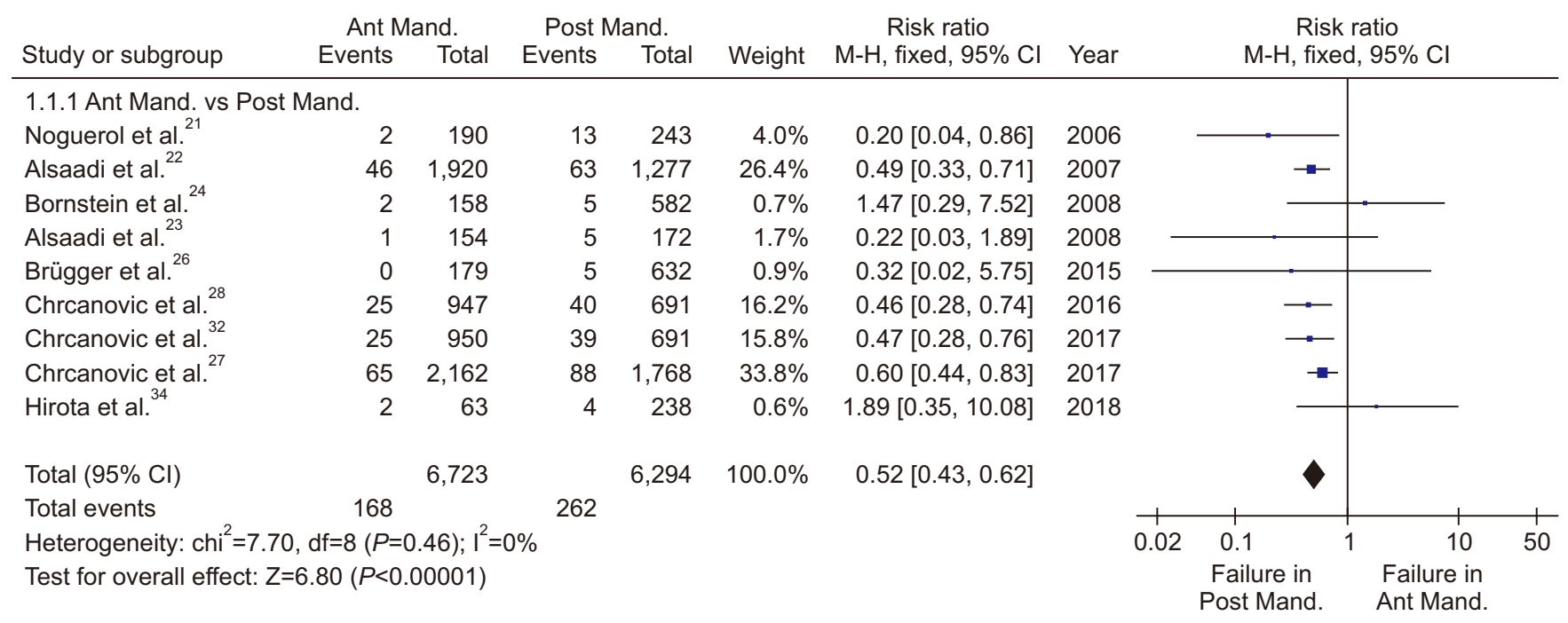

Fig. 6. Forest plot comparison: Anterior mandibular region (Ant Mand.) versus posterior mandibular region (Post Mand.) in early implant failures.

Atef Abdel Hameed Fouda: The impact of the alveolar bone sites on early implant failure: a systematic review with meta-analysis. J Korean Assoc Oral Maxillofac Surg 2020

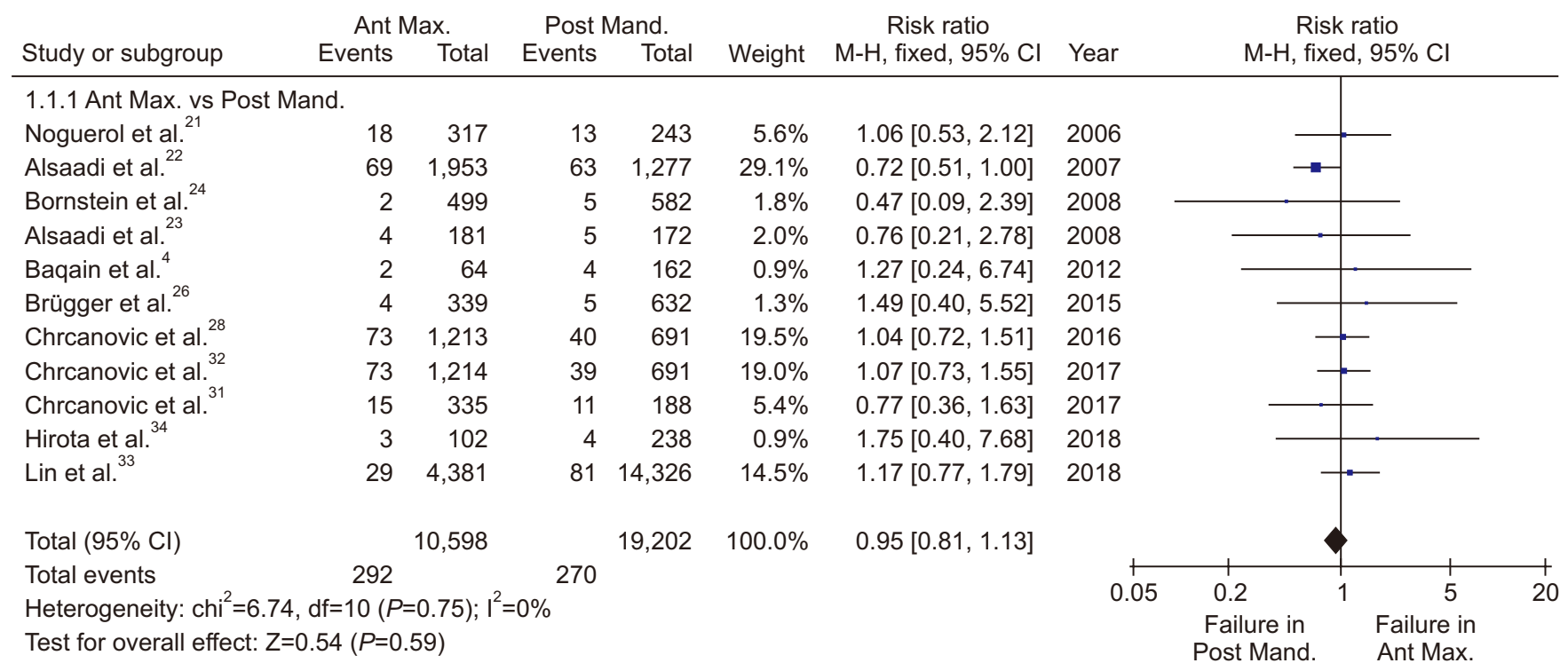

Fig. 7. Forest plot comparison: Posterior mandibular region (Post Mand.) versus anterior maxillary region (Ant Max.) in early implant failures. Atef Abdel Hameed Fouda: The impact of the alveolar bone sites on early implant failure: a systematic review with meta-analysis. J Korean Assoc Oral Maxillofac Surg 2020 
mandible (2.5\%) compared to 356 failed implants in the maxillary posterior region (4.8\%).

Total subgroup analysis of the 12 studies applying a fixed effect, RR, and CI of 95\% revealed significant failure in the posterior maxilla compared to the anterior mandible (RR 0.45 ; 95\% CI [0.37, 0.53]; $P<0.00001 ; \mathrm{I}^{2}=0 \%$ ).(Fig. 8)

The RD analysis reported a 3\% higher risk failure in the posterior maxillary region compared to the anterior mandibular region.

\section{Publication bias}

Funnel plots were used to visually assess publication bias.

\section{Discussion}

EIF depends on the surgeon's skill, the type and site of implant, the condition of the bone, and the circumstances during the healing process.

The primary aim of this review was to explore any association between the site of implantation and EIF by comparing studies with implants inserted in different regions in either the upper and lower jaws to determine the most influential site on implant early failure and to change the practice of using a single implant design for all anatomical regions.

EIFs occur due to formation of fibrous tissue before osseointegration or micro-movements of the implants during heal- ing. EIFs are linked to the quality of bone, implant design, bacterial invasion, or improper site preparation that impede the osseointegration process.

In the current review, studies of a total of 78,230 dental implants with recorded failures after insertion in different anatomical regions were analyzed using a fixed effects model. Studies could not ascertain all the confounding factors that could lead to EIFs.

In this review, we attempted to exclude studies with implants placed in immediate post-extraction sites according to the results of Quirynen et al. ${ }^{37}$ who linked pathology of the extracted tooth to early failure of the inserted implant. Furthermore, studies that included implants inserted after sinus elevation or bone expansion were excluded from analysis because of the presence of multiple confounding factors.

The percentage of EIFs in this review was $2.55 \%$, and the published failure incidence varied from $2.5 \%$ to $3.8 \%{ }^{22,38-42}$.

In agreement with $\mathrm{Kim}$ and $\mathrm{Lee}^{43}$, the maxilla has a thinner cortical plate and lower bone density than the mandible. Sites with poor bone quality may be at risk of inability to establish primary stability of the implants resulting in EIFs. High failure rates in the mandibular posterior region have been determined to be caused by overheating of the bone ${ }^{44}$.

Bone type affects EIF rates, yet some studies included implants inserted in poor quality bone without impacting the implant success rate ${ }^{23,45}$. A study conducted by Baqain et al. ${ }^{4}$ reported no difference in early failures for implants inserted

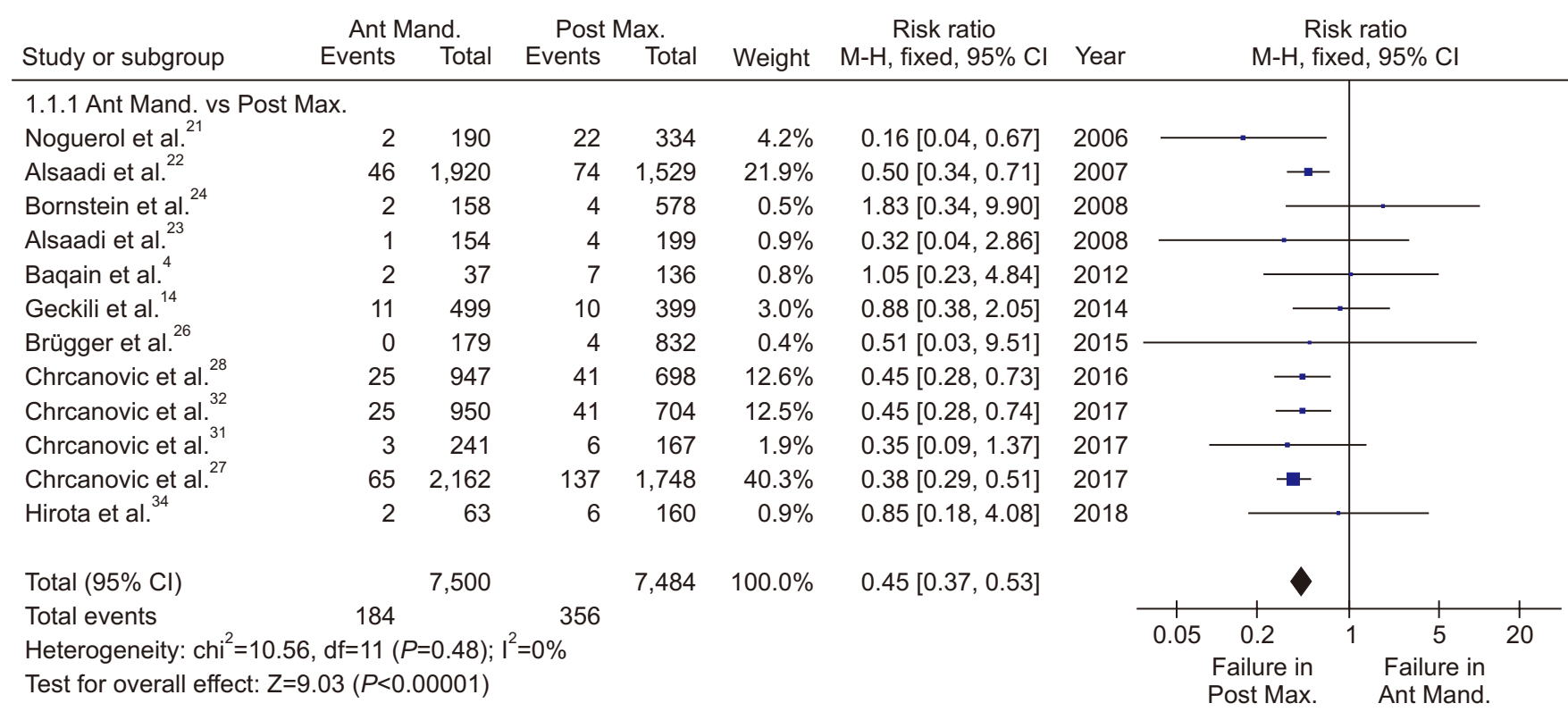

Fig. 8. Forest plot comparison: Anterior mandibular region (Ant Mand.) versus posterior maxillary region (Post Max.) in early implant failures. Atef Abdel Hameed Fouda: The impact of the alveolar bone sites on early implant failure: a systematic review with meta-analysis. J Korean Assoc Oral Maxillofac Surg 2020 
in different bone types. Alsaadi et al. ${ }^{22,23}$ concluded that the implant site did not exhibit a significant effect on implant failures in their prospective study. Esposito et al. ${ }^{6}$ found that the success rate in the posterior maxillary region was the highest of the anterior maxillary region, posterior mandible, and anterior mandible. The results of the subgroup analysis in the current review agree with them which revealed a nonsignificant difference in failure between the posterior maxilla and posterior mandible (RR 1.07; 95\% CI [0.92, 1.25]; $P=0.68 ; \mathrm{I}^{2}=0 \%$ ) rejecting the hypothesis of bone density.

The results of the current review confirmed that the failure rate of maxillary implants was significantly higher than that of mandibular implants, and implants placed in the maxilla result in two times more failures than those in the mandible.

This review examined the role of implant site as a risk factor responsible for early implant loss in both jaw bones. A RD of $1 \%$ was detected between the upper and lower jaws.

Subgroup analysis of the anterior maxillary region compared with the anterior mandibular region revealed more frequent EIF within the upper anterior region (6.2\%) compared to the lower anterior region (2.5\%). Applying a fixed effect and RR, a significant failure in the anterior maxilla was exhibited compared to the anterior mandible (RR 2.44; 95\% CI $\left.[2.04,2.91] ; P<0.00001 ; \mathrm{I}^{2}=0 \%\right)$. A $3 \% \mathrm{RD}$ was detected between the mandibular and maxillary anterior regions. This could be explained by the larger number of risk factors possible for the anterior maxillary region compared to any other site, in the form of lower bone density, undesirable forces due to angulation of the implants, and thin cortical plates. The anterior maxillary region exhibited the lowest success rate compared to the posterior maxillary, posterior mandible, and anterior mandible regions.

Posterior implants in both arches have also shown significant failures compared to anterior mandibular implants.

Restriction of the risk of failure to the insertion site is unfair, but it helps in improving implant designs and surgical techniques to be modified according to insertion site.

Retrospective studies may have the risk of missing data and inaccurate interpretation of the results. Narrowing of the inclusion criteria increases the homogeneity between studies but could result in exclusion of some trials with valuable data.

The percentage of EIF is high compared to failures after loading. This review identified a single primary factor for such failures, and the author recommends further evaluations of implantation site is consideration of other risk factors.

Construction of variable implant designs according to the bone quality of each anatomical site is recommended. Implants designed for high-risk regions should differ in design and surface characteristics compared to those inserted in low failure rate regions.

Implants that depend on bone compression to increase primary stability are not suitable in areas with dense bone. Finally, recently introduced modified implants in the form of nano-topographic surface treatments, high surface wettability, and growth factors are suggested to be placed in highrisk areas such as the anterior maxillary region based on cost benefits.

\section{Conclusion}

The anterior maxilla is a critical site for EIFs compared to other alveolar sites. Implants inserted in the anterior mandible exhibited the best success rate compared with other alveolar bone sites.

The maxilla is riskier than the mandible regarding EIFs, yet the difference between the posterior maxillary and the posterior mandibular regions is not significant. The RD between the maxilla and mandible is related to the high-risk anterior maxillary region.

\section{Author's Contributions}

A.A.H.F. participated in study design, data collection, statistical analysis of the results, and wrote the manuscript.

\section{Acknowledgements}

The author would like to thank Prof. Ghada El Shazly for her help in this review by verifying the inclusion and exclusion of studies.

\section{Conflict of Interest}

No potential conflict of interest relevant to this article was reported.

\section{References}

1. Goodacre CJ, Bernal G, Rungcharassaeng K, Kan JY. Clinical complications with implants and implant prostheses. J Prosthet Dent 2003;90:121-32.

2. Olate S, Lyrio MC, de Moraes M, Mazzonetto R, Moreira RW. Influence of diameter and length of implant on early dental implant failure. J Oral Maxillofac Surg 2010;68:414-9. 
3. Sakka S, Baroudi K, Nassani MZ. Factors associated with early and late failure of dental implants. J Investig Clin Dent 2012;3:25861.

4. Baqain ZH, Moqbel WY, Sawair FA. Early dental implant failure: risk factors. Br J Oral Maxillofac Surg 2012;50:239-43.

5. Olmedo-Gaya MV, Manzano-Moreno FJ, Cañaveral-Cavero E, de Dios Luna-del Castillo J, Vallecillo-Capilla M. Risk factors associated with early implant failure: a 5-year retrospective clinical study. J Prosthet Dent 2016;115:150-5.

6. Esposito M, Hirsch JM, Lekholm U, Thomsen P. Biological factors contributing to failures of osseointegrated oral implants. (II). Etiopathogenesis. Eur J Oral Sci 1998;106:721-64.

7. Hadi S, Ashfaq N, Bey A, Khan S. Biological factors responsible for failure of osseointegration in oral implants. Biol Med 2011;3:164-70.

8. Moheng P, Feryn JM. Clinical and biologic factors related to oral implant failure: a 2-year follow-up study. Implant Dent 2005;14:281-8.

9. Becker W, Becker BE, Alsuwyed A, Al-Mubarak S. Long-term evaluation of 282 implants in maxillary and mandibular molar positions: a prospective study. J Periodontol 1999;70:896-901.

10. Oztel M, Bilski WM, Bilski A. Risk factors associated with dental implant failure: a Study of 302 implants placed in a regional center. J Contemp Dent Pract 2017;18:705-9.

11. Bahat $\mathrm{O}$. Brånemark system implants in the posterior maxilla: clinical study of 660 implants followed for 5 to 12 years. Int J Oral Maxillofac Implants 2000;15:646-53.

12. Moy PK, Medina D, Shetty V, Aghaloo TL. Dental implant failure rates and associated risk factors. Int J Oral Maxillofac Implants 2005;20:569-77.

13. Levin L, Sadet P, Grossmann Y. A retrospective evaluation of 1,387 single-tooth implants: a 6-year follow-up. J Periodontol 2006;77:2080-3.

14. Geckili O, Bilhan H, Geckili E, Cilingir A, Mumcu E, Bural C. Evaluation of possible prognostic factors for the success, survival, and failure of dental implants. Implant Dent 2014;23:44-50.

15. Lang LA, Hansen SE, Olvera N, Teich S. A comparison of implant complications and failures between the maxilla and the mandible. $\mathrm{J}$ Prosthet Dent 2019;121:611-7.

16. Hinode D, Tanabe S, Yokoyama M, Fujisawa K, Yamauchi E, Miyamoto Y. Influence of smoking on osseointegrated implant failure: a meta-analysis. Clin Oral Implants Res 2006;17:473-8.

17. Kang DY, Kim M, Lee SJ, Cho IW, Shin HS, Caballé-Serrano J, et al. Early implant failure: a retrospective analysis of contributing factors. J Periodontal Implant Sci 2019;49:287-98.

18. Moher D, Liberati A, Tetzlaff J, Altman DG. Preferred reporting items for systematic reviews and meta-analyses: the PRISMA statement. PLoS Med 2009;6:e1000097.

19. Higgins JPT, Green S. Cochrane Handbook for Systematic Reviews of Interventions Version 5.1.0 [Internet]. London: The Cochrane Collaboration [cited 2019 Sep]. Available from: https:// handbook-5-1.cochrane.org/.

20. Lambert PM, Morris HF, Ochi S. The influence of smoking on 3-year clinical success of osseointegrated dental implants. Ann Periodontol 2000;5:79-89.

21. Noguerol B, Muñoz R, Mesa F, de Dios Luna J, O'Valle F. Early implant failure. Prognostic capacity of Periotest: retrospective study of a large sample. Clin Oral Implants Res 2006;17:459-64.

22. Alsaadi G, Quirynen M, Komárek A, van Steenberghe D. Impact of local and systemic factors on the incidence of oral implant failures, up to abutment connection. J Clin Periodontol 2007;34:610-7.

23. Alsaadi G, Quirynen M, Michiles K, Teughels W, Komárek A, van Steenberghe D. Impact of local and systemic factors on the incidence of failures up to abutment connection with modified surface oral implants. J Clin Periodontol 2008;35:51-7.

24. Bornstein MM, Halbritter S, Harnisch H, Weber HP, Buser D. A retrospective analysis of patients referred for implant placement to a specialty clinic: indications, surgical procedures, and early failures. Int J Oral Maxillofac Implants 2008;23:1109-16.

25. Mangano F, Macchi A, Caprioglio A, Sammons RL, Piattelli A, Mangano C. Survival and complication rates of fixed restorations supported by locking-taper implants: a prospective study with 1 to 10 years of follow-up. J Prosthodont 2014;23:434-44.

26. Brügger OE, Bornstein MM, Kuchler U, Janner SF, Chappuis V, Buser D. Implant therapy in a surgical specialty clinic: an analysis of patients, indications, surgical procedures, risk factors, and early failures. Int J Oral Maxillofac Implants 2015;30:151-60.

27. Chrcanovic BR, Kisch J, Albrektsson T, Wennerberg A. Impact of different surgeons on dental implant failure. Int J Prosthodont 2017;30:445-54.

28. Chrcanovic BR, Kisch J, Albrektsson T, Wennerberg A. Bruxism and dental implant failures: a multilevel mixed effects parametric survival analysis approach. J Oral Rehabil 2016;43:813-23.

29. Borba M, Deluiz D, Lourenço EJV, Oliveira L, Tannure PN. Risk factors for implant failure: a retrospective study in an educational institution using GEE analyses. Braz Oral Res 2017;31:e69.

30. Hickin MP, Shariff JA, Jennette PJ, Finkelstein J, Papapanou PN. Incidence and determinants of dental implant failure: a review of electronic health records in a U.S. dental school. J Dent Educ 2017;81:1233-42.

31. Chrcanovic BR, Kisch J, Albrektsson T, Wennerberg A. Is the intake of selective serotonin reuptake inhibitors associated with an increased risk of dental implant failure? Int J Oral Maxillofac Surg 2017;46:782-8.

32. Chrcanovic BR, Kisch J, Albrektsson T, Wennerberg A. Intake of proton pump inhibitors is associated with an increased risk of dental implant failure. Int J Oral Maxillofac Implants 2017;32:1097102.

33. Lin G, Ye S, Liu F, He F. A retrospective study of 30,959 implants: risk factors associated with early and late implant loss. J Clin Periodontol 2018;45:733-43.

34. Hirota M, Ozawa T, Iwai T, Ogawa T, Tohnai I. Effect of photofunctionalization on early implant failure. Int J Oral Maxillofac Implants 2018;33:1098-102.

35. Chatzopoulos GS, Wolff LF. Symptoms of temporomandibular disorder, self-reported bruxism, and the risk of implant failure: a retrospective analysis. Cranio 2020;38:50-7.

36. Hasegawa T, Kawabata S, Takeda D, Iwata E, Saito I, Arimoto S, et al. Survival of Brånemark System Mk III implants and analysis of risk factors associated with implant failure. Int J Oral Maxillofac Surg 2017;46:267-73.

37. Quirynen M, Vogels R, Alsaadi G, Naert I, Jacobs R, van Steenberghe D. Predisposing conditions for retrograde peri-implantitis, and treatment suggestions. Clin Oral Implants Res 2005;16:599-608.

38. Berglundh T, Persson L, Klinge B. A systematic review of the incidence of biological and technical complications in implant dentistry reported in prospective longitudinal studies of at least 5 years. J Clin Periodontol 2002;29 Suppl 3:197-212; discussion 232-3.

39. Bornstein MM, Cionca N, Mombelli A. Systemic conditions and treatments as risks for implant therapy. Int J Oral Maxillofac Implants 2009;24 Suppl:12-27.

40. Koldsland OC, Scheie AA, Aass AM. Prevalence of implant loss and the influence of associated factors. J Periodontol 2009;80:106975.

41. Huynh-Ba G, Friedberg JR, Vogiatzi D, Ioannidou E. Implant failure predictors in the posterior maxilla: a retrospective study of 273 consecutive implants. J Periodontol 2008;79:2256-61.

42. Shrier I, Boivin JF, Steele RJ, Platt RW, Furlan A, Kakuma R, et al. Should meta-analyses of interventions include observational studies in addition to randomized controlled trials? A critical examination of underlying principles. Am J Epidemiol 2007;15:1203-9.

43. Kim BJ, Lee JH. The retrospective study of survival rate of implants with maxillary sinus floor elevation. J Korean Assoc Oral Maxillofac Surg 2010;36:108-18. 
44. Park SW, Jang SM, Choi BH, Son HN, Park BC, Kim CH, et al. The study of bone density assessment on dental implant sites. J Korean Assoc Oral Maxillofac Surg 2010;36:417-22.

45. Ryu SH, Kim BS, Jung S, Han MS, Kook MS, Ohk SH, et al. Expression of osteoclastogenesis related factors in dental implant patients. J Korean Assoc Oral Maxillofac Surg 2010;36:386-91.
How to cite this article: Fouda AAH. The impact of the alveolar bone sites on early implant failure: a systematic review with metaanalysis. J Korean Assoc Oral Maxillofac Surg 2020;46:162-173. https://doi.org/10.5125/jkaoms.2020.46.3.162 